\title{
COMPARATIVE EFFICACY OF NASAL STEROID IN COMBINATION WITH AN ANTIHISTAMINE VERSUS STEROID ALONE AS NASAL SPRAY IN NASAL POLYPOSIS
}

\author{
M. Mahendra Kumar1 ${ }^{1}$ S. Muneeruddin Ahmed², Md. Naveed Ahmed ${ }^{3}$, Durga Prasad4
}

\section{HOW TO CITE THIS ARTICLE:}

M. Mahendra Kumar, S. Muneeruddin Ahmed, Md. Naveed Ahmed, Durga Prasad. "Comparative Efficacy of Nasal Steroid in Combination with an Antihistamine Versus Steroid alone as Nasal Spray in Nasal Polyposis". Journal of Evolution of Medical and Dental Sciences 2014; Vol. 3, Issue 27, July 07; Page: 7595-7604,

DOI: $10.14260 /$ jemds/2014/2942

ABSTRACT: Nasal polyposis is a disease entity characterized by development of benign growths arising either from the nasal mucosa or from any of the Para-nasal sinuses alone or in combination. These out growths are associated with oedema, fibrosis, reduced vascularization, decreased number of glands as well as nerve endings and damaged epithelium. The cause of nasal polyposis is not completely understood; however, it is frequently associated with asthma and intolerance to aspirin. The condition is characterized by eosinophil inflammation: approximately $65 \%$ to $90 \%$ of polyps is classified histologically as eosinophilic. The symptoms of nasal polyposis include nasal obstruction, watery discharge and impairment of sense of smell. The objectives for the management of the condition include elimination or reduction in the size of polyps followed by reestablishment of an open nasal airway and nasal breathing, improvement or restoration of sense of smell and ultimately prevention of polyp recurrence. In nasal polyposis, topical nasal corticosteroids are considered the medical treatment of choice and several different intranasal corticosteroids in combination with antihistamines have been investigated with regard to both effect on symptoms and reduction in polyp size. These benefits maybe attributed at least in part, to the effect of topical corticosteroids on decreasing eosinophilic infiltration in the nasal mucosa. The objective of the present study is to evaluate the comparative efficacy of local nasal steroids alone and in combination with an antihistamine.

KEYWORDS: Polyposis, Fluticasone, Azelastine, Nasal spray, Rhinorrhoea, metered dosage,

MATERIALS AND METHODS: The present study is a prospective study to evaluate the role of steroids in combination with Antihistamine in the form of nasal spray used in selective patients suffering from Nasal polyposis prior to surgical procedure. Comparative efficacy of steroid nasal spray versus combination of steroid with antihistamine nasal spray in nasal polyposis is also evaluated. The present Study includes 60 patients with Nasal polyposis in nose and Para-nasal sinuses treated in the department of ENT, Government General Hospital attached to Kurnool Medical College, Kurnool.

This Study was conducted for a period of 2 years from June 2010- November 2012. This study is a prospective, comparative, study. 60 patients are selected for this study among 7054 patients who attended the Outpatient department with complaints related to nose and Para-nasal diseases constituting to $0.85 \%$. All the patients are subjected to detailed history taking, clinical examination, endoscopic examination, radiological investigation, counseling for pre-operative medical management and regular follow-up. The Data was collected in a standard format for calculation and ready reckoning. DNE and endoscopic grading of polyps is done. Patients are given a simple 


\section{REVIEW ARTICLE}

questionnaire relating to symptoms in order to grade the severity of complaints which are depicted in a chart for easy gradation and post treatment evaluation. All patients were subjected to DNE and endoscopic grading of nasal polypi every month. In the present study the follow up period is for 6 months.

All patients were then required to fill the symptom chart. In Group I 30 patients were administered Steroid (Fluticasone propionate) in combination with an Antihistamine (Azelastine) nasal spray over a period of 6months. In group II patients were given Steroid (Fluticasone propionate) nasal spray alone. Both the groups were examined and evaluated symptom wise at monthly intervals.

In the study following inclusion and exclusion criteria were applied.

\section{Inclusion Criteria:}

*Age 18 - 55 years

*All socio economic status

*Both sexes

\section{Exclusion Criteria:}

*Antro- choanal polyps

*Acute sinusitis

*Previously operated cases (making endoscopic staging difficult)

Investigations: Hemoglobin, total count, differential count, bleeding time, clotting time, ESR, platelet count, urine albumin and sugar.

\section{Radiological Investigations:}

*X-ray Para-nasal sinuses

*CT scan of Para-nasal sinuses

Diagnostic nasal endoscopy (DNE)

OBSERVATIONS: A total number of 60 patients are included in the present study conducted from June 2010 to November 2012. 30348 patients attended the ENT out Patient Department in government general hospital, Kurnool. Among them 7054 patients presented with symptoms related to nose. 60 patients among the 7054 were selected randomly for our study which amounts to $0.85 \%$. The selected cases are divided randomly into two groups having 30 subjects each. Group I consists of $70 \%$ of males $(n=21)$ and $30 \%$ of females $(n=09)$.group II consists of $80 \%$ of males $(n=24)$ and $20 \%$ of females ( $\mathrm{n}=06)$; (Table III).

Group I consists of $40 \%$ within 20 -30- years of age, $36.66 \%$ within $31-40$ of age $20 \%$ are from 41-50 years of age group and 3.33\%above 50 years of age group; (Table IV)

Group II consists of 50\% within 20-30- years of age, $36.66 \%$ within $31-40$ of age $10 \%$ are from $41-50$ years of age group and $3.33 \%$ above 50 years. (Table IV) 
Symptoms: GROUP I: In group I $26.6 \%$ of patients presented with nasal obstruction of mild degree. It is in moderate degree in $23.3 \%$ of cases and $50 \%$ of patients are having severe degree of nasal obstruction. $33.6 \%$ of patients presented with nasal discharge of mild degree, $403.3 \%$ of the patients presented with moderate degree and 20\% had severe degree. Excessive sneezing is elicited in 30\% of patients which is of mild degree, moderate degree of sneezing in $30 \%$ of patients and $30 \%$ of patients are having severe degree of sneezing. Headache was the presenting complaint in $53.3 \%$ of patients. $40 \%$ of patients had disturbances of smell. (Table I)

GROUP II: In this group $43.3 \%$ of patients had severe nasal obstruction, $30 \%$ of patients had mild nasal obstruction and $26.6 \%$ had in moderate degrees. Mild degree of nasal discharge was present in $43.3 \%$ of patients; moderate degree in $30 \%$ and $26.6 \%$ of patients had severe degree of nasal discharge. Excessive sneezing and watering from nose is complained by $26.6 \%$ of patients which is of mild degree. It is of moderate degree in $33.3 \%$ of patients. Severe degree of excessive sneezing was found in $40 \%$ of the patients. Headache was presented in $33.3 \%$ of patients. Loss of sense of smell was in $43.3 \%$ of the patients. (Table I)

GRADING OF POLYPI PRIOR TO MEDICAL TREATMENT-GROUP I, (Table II): In group I 33.3\% were found to be of Grade I, $30 \%$ of the patients are found to have Grade II and $36.6 \%$ of them are of Grade III.

GRADING OF POLYPI PRIOR TO MEDICAL TREATMENT-GROUP II, (Table II): In group II patients Grade I type of Polypi were found in 30\%. $26.6 \%$ of patients were having polyps of Grade 2 and grade III severity was seen in $43.3 \%$ of patients.

X RAY FINDINGS: In group I 26 (86.6\%) patients were found to have haziness of maxillary antrum on plain $x$ ray PNS, whereas 21 (70\%) Patients of group II had haziness of maxillary antrum.

CT SCAN FINDINGS: The CT scan analysis showed In Group 1 26(86.6\%) patients had positive CT scan findings where as it were 21(70\%) patients belonging to Group II. Applying the Lunds system of CT scan scoring it was found that the patients of group I who had positive CT scan findings revealed a score of $0-6$ in $20(66.6 \%)$. In $10(33.3 \%)$ patients the score was of 6-12. In group II the CT scan scoring was between 0-6 in 17(56.6\%) patients, whereas the score of 6-12 was observed in $14(46.6 \%)$ patients.

All the patients are now counseled for surgery with initial treatment with Local Steroid spray either alone or in combination with an antihistamine (Azelastine). Group I patients are prescribed a combination of Azelastine with Fluticasone. Group II patients are prescribed with a nasal spray containing only a steroid (Fluticasone).

They are advised to use the spray with a single sniff in each nostril twice a day. Prior use of Local nasal decongestant is advised in those patients with Grade II and Grade III Polypi. These sprays come with a fixed delivery of dose usually the steroid delivered is $75 \mathrm{mcg}$ with each sniff. Patients of both the groups are prescribed a common medication consisting of an Antibiotic usually Azithromycin $500 \mathrm{mg}$ for a period of 6 days, Systemic steroid of Methyl-prednisone 4mgdaily twice for a period of 1 week and an antihistamine usually Levocetrizine $10 / 5 \mathrm{mg}$ daily. The antihistamine is continued throughout the period of the medical management and it is also advised even after surgery. 
The patients are advised to use the spray as per the instruction given to them for one month. They are given a demonstration on the correct usage of the prescribed spray. All the patients are instructed to take an immediate consultation if any adverse reactions like itching, burning or discomfort occurs while using the spray.

The patients are reviewed after one month. A thorough history taking and clinical examination is done. They are subjected to diagnostic nasal endoscopy and Polypi are graded again.

(Table V) In group I at the end of the study on evaluation of grading of polypi, it was observed that 5 patients out of 11 patients of grade III had regression of polypi. 6 patients out of 9 with grade II polypi showed regression. 6 out of 10 Patients of grade I showed regression. (Table VI) Likewise in group II 6 out of 13 patients of grade III showed regression of polypi. 3 out of 8 patients of grade II showed regression whereas all the 4 out of 9 patients of grade I showed regression.

In regard to the symptom of nasal obstruction among the patients in group I, 8 patients out of 15 with severe obstruction experienced relief, 3 out of 7 patients of moderate degree of obstruction responded with relief. All the 8 patients with mild obstruction responded with relief (Table V). In group II 6 out of 13 Patients with severe nasal obstruction, 2 out of 8 patients of moderate obstruction and 5 out of 9 patients of mild severity replied in their questionnaire as to have near total relief of nasal obstruction (Table VI).

In group I subjective evaluation at the end of the study in relation to the symptom of excessive sneezing, 8 out of 9 patients of mild degree, 7 out of 12 patients of moderate degree and 4 out of 9 patients of severe grade responded near total relief. In group II 3 out of 8 patients of mild degree, 3 out of 10 patients of moderate degree and 5 out of 12 patients of severe grade of excessive sneezing, responded near total relief.

(Table V)In group I subjective evaluation at the end of the study in relation to the symptom of Rhinorrhoea, all the 6 patients out of 11 with mild degree, 6 out of 13 patients of moderate degree and 4 out of 6 patients of severe grade responded near total relief. (Table VI) In group II 4 out of 13 patients of mild degree, 3 out of 9 patients of moderate degree and 2 out of 8 patients of severe grade of Rhinorrhoea, responded near total relief.

DISCUSSION: Nasal polyposis is a common disease affecting up to $4 \%$ percent of the population. Their aetiology remains unclear, but they are known to have associations with Nasal allergy, asthma, infection, cystic fibrosis, and aspirin sensitivity. They present with nasal obstruction, anosmia, rhinorrhoea, post nasal drip and less commonly facial pain. Clinical examination reveals single or multiple grey polypoid masses in the nasal cavity.

Computerized tomography allows evaluation of the extent of the disease and is essential if surgical treatment is to be considered. Management of polyposis involves a combination of medical therapy and surgery. An association between polyposis and fungal cultures has been established for many years ${ }^{1}$ Safirstein et al 1976. Further reports linked this finding with allergic Bronchopulmonary aspergillosis ${ }^{2}$ Millar et al 1981. This recognition led to the term 'allergic fungal Sinusitis'.

In the general population, the prevalence of NP is considered to be around $4 \%{ }^{3}$ (Hedman et al 1999). In cadaveric studies, this prevalence has been shown to be as high as $40 \%{ }^{4}$ Laren et al 1994. They predominantly affect adults and usually present in patients older than 20 . There is at least a 2:1 male to female preponderance. Up to a third of NP patients have asthma, whereas polyps are only found in $7 \%$ of asthmatics ${ }^{5}$ Settipane et al 1996. 


\section{REVIEW ARTICLE}

In the present study the incidence was $0.85 \%$ of the 7054 patients attending for nasal complaints to the outpatient department. The prevalence of nasal polyposis in general population in our study is $3.32 \%$. Male to female preponderance of nasal polypi in our study is 3:1. Plain X-rays are insensitive and of no value in the diagnosis of NP but they may show opacification of the affected sinuses $^{6}$ Iinuma et al 1994. In our study an average of $77.5 \%$ of both the groups of patients showed haziness of maxillary antrum on plain $x$ ray PNS.

A range of staging systems for CT scanning have been described, the most commonly used being the Lund-Mackay system ${ }^{7}$ Lund et al 1993. This system relies on a score of $0-2$ dependent on the absence, partial, or complete opacification of each sinus system and of the vital osteo- meatal complex deriving a maximum score of 12 per side. By applying Lunds classification for CT Scan findings in our study it was found that $2 / 3$ rd of patients had a score less than 6 , and a score of greater than 6 was found in 1/3rd of study population with positive CT Scan findings.

Therapy for NP involves a combination of observation, medical, and surgical treatments depending on individual case assessment. In general, patients are treated medically in the primary care setting before consideration of surgical procedures by an otolaryngologist. The aims of treatment are to eliminate or significantly reduce the size of the NP resulting in relief of nasal obstruction, nasal discharge, headache, improvement in sinus drainage, restoration of olfaction and taste.

Azelastine was used in the nasal spray form in combination with fluticasone propionate. Azelastine is more than just anti-histamine. It exhibits a very fast and long-acting effect based on a triple mode of action, with anti-inflammatory and mast cell stabilizing properties in addition to its anti-allergic effects Bernstein ${ }^{8}$ 2007; Lee and Corren 2007. For example, Azelastine inhibits the activation of cultured mast cells and release of interleukin (IL)-6, tryptase, and histamine Duraisamy Kempuraj et $\mathrm{al}^{9} 2002$.

Ratner PH, Hampel F, Van Bavel J, Amar NJ, Daftary P, Wheeler W, Sacks $\mathrm{H}^{10}$ conducted a study of 151 patients with moderate to severe nasal symptoms, randomized to treatment with Azelastine and fluticasone, fluticasone nasal spray alone and Azelastine nasal spray alone, All 3 groups had statistically significant $(\mathrm{P}<.001)$ improvements from their baseline TNSS after 2 weeks of treatment. The TNSS improved 27.1\% with fluticasone nasal spray, 24.8\% with Azelastine nasal spray, and $37.9 \%$ with the 2 agents in combination ( $\mathrm{P}<.05$ vs either agent alone). All 3 treatments were well tolerated.

Quoting from the Journal Asthma and Allergy 2010 3: 19-28; "Seasonal allergic rhinitis: fluticasone propionate and fluticasone furoate therapy evaluated"; the excellent pharmacodynamic and pharmacokinetic properties along with safety have given FP a key position. This impressive therapeutic and safety profile is a reflection of its rapid and extensive uptake by airway tissue, marked affinity for the GR and almost undetectable systemic bioavailability.

The propionate ester side chain renders FP highly lipophilic. Such lipophilicity is a key determinant of its pharmacological profile and allows the drug to bind tissue rapidly and strongly with more prolonged retention than more hydrophilic molecules such as budesonide and hydrocortisone.

PHILADELPHIA, PA -- November 15, 2006 -- Azelastine nasal spray in combination with fluticasone propionate nasal spray provided roughly $40 \%$ more relief in patients with allergy to 
Texas mountain cedar compared with fluticasone nasal spray alone, investigators reported here at the 2006 Annual Meeting of the American College of Allergy, Asthma and Immunology (ACAAI).

The combination therapy improved symptoms within 24 hours, with increasing improvement seen during the entire 14-day duration of the trial, said investigator ${ }^{10}$ Paul Ratner, MD, allergist in private practice, and medical director, Sylvana Research Associates, San Antonio, Texas. The combination of Azelastine and fluticasone was "extremely well tolerated," Dr. Ratner added in an oral presentation on November 11th.

In our study incidence of nasal obstruction has reduced by $65.4 \%$ in group I where a combination of FP steroid and antihistamine was used compared to $42.9 \%$ in group II where steroid FP alone was used.

Excessive sneezing has reduced by $63.86 \%$ in group I compared to $36.3 \%$ in group II. Incidence of headaches was 5.8\% for patients receiving both nasal sprays, and about 4\% for patient who received either agent alone. No other adverse events were reported by more than 1 patient in any treatment group, and no patients discontinued due to adverse events during the trial.

Djupesland PG1, VlckovaI, ${ }^{11}$ Little et al in their study opined that little information exists on the impact of baseline polyp size and previous nasal surgery on the efficacy of intranasal steroids. Their study was designed to investigate whether baseline polyp size and previous nasal surgery influence the efficacy of an intranasal steroid delivered with a novel device. It was reported that a highly significant and progressive reduction in summed polyp size was observed for Opt-FP versus placebo in all three polyp size subgroups ( $\mathrm{p}<0.001)$.

Djupesland PG1, Vlckova I, Hewson G.FESS4, in their study concluded that Symptoms of nasal obstruction, rhinorrhea, postnasal drip, and loss of smell were reduced in the FPND group ( $\mathrm{P}<.05)$. Peak nasal inspiratory flow scores increased significantly $(\mathrm{P}<.01)$. Polyp volume decreased in the FPND group ( $\mathrm{P}<.05)$, and computed tomographic scores improved in both groups $(\mathrm{P}<.05)$.

In the present study the Group I patients where Fluticasone propionate in combination with Azelastine was used showed better results in terms with improvement in Nasal obstruction, Rhinorrhoea, Excessive sneezing and Regression of polypi, when compared to the Group II patients.

Pearson statistical analysis is applied to calculate the correlation between these two groups, it showed $r^{2}$ 0.75; nasal obstruction for Group I and $r 2=0.62$ for group II. Similarly the $r^{2}$ for Rhinorrhoea, Excessive sneezing and regression of Polypi was 0.99, 0.5 and 0.98 respectively for group I and $0.98,0.87$ and 0.98 for group II, which is significant. (value more than 0.37 is termed significant).

Student t test to analyze statistical significance between the 2 groups in the treatment of Nasal Polyposis showed a significant difference in their role as a pre-operative mode to control the polyposis. The $\mathrm{p}$ value was 0.06 for nasal obstruction, 0.015 for Rhinorrhoea and 0.034 for Excessive sneezing and 0.003 for regression of polypi in group I. similarly for group II the values are 0.069 , $0.035,0.031$ and 0.039 . (P value less than 0.06 is significant).

As Azelastine and Fluticasone propionate in combination is effective as a pre-operative intra nasal spray to reduce the size of the polypi which will help in FESS.

CONCLUSIONS: Efficacy of using a combination of a local steroid and an antihistamine in the medical management of Nasal polyposis is searched in the literature and it is found that not many studies are 


\section{REVIEW ARTICLE}

forth coming; hence this study though a small group is observed gives an insight to the usage of Combination nasal spray of Fluticasone and Azelastine.

But it needs further elaborate and in depth probing. In nasal polyposis, topical nasal corticosteroids in combination with an antihistamine can be considered as the medical treatment of choice. Both the medications that were used in the study are well tolerated and no side effects have been reported by the study population.

In this study, significant decrease in polyp size and alleviation of symptoms like nasal obstruction, nasal discharge and excessive sneezing are observed in both the groups. However, approximately $2 / 3 \mathrm{rd}$ of patients using combination of local steroid and anti-histamine experienced a significant change in the polyp size and relief of symptoms compared to $1 / 3 \mathrm{rd}$ of patients using Local nasal steroid alone.

Statistical significance suggests that the combination of nasal steroid with antihistamine is superior to local nasal steroid spray alone in reducing the poly size; ( $p$ value $<0.003$ ). Antihistamine nasal spray in combination provides a good therapeutic benefit for patients with nasal polyposis compared with therapy with local steroid alone.

ACKNOWLEDGEMENT: We Thank the Superintendent and Principal Government General Hospital and Kurnool Medical College, Kurnool respectively for permitting us to undertake the study. We thank all the residents and nursing staff for taking care of the patients during immediate post operative period.

\section{REFERENCES:}

1. Safirstein et al, "An association between polyposis and fungal cultures has been established for many years". www.ncbi.nlm.nih.gov; Ther Clin Risk Manag. Apr 2008; 4(2): 441-451. Published online.

2. Millar et al: An association between polyposis and fungal cultures has been established for many years 1981; www.ncbi.nlm.nih.gov; Ther Clin Risk Manag > v. 4 (2); Apr 2008.

3. Hedman et al Text Book of Allergy and Allergic diseases volume 1 part 9 Allergic Rhinoconjuncti -vitis and Immunotheray; 1390.

4. Laren PL, Tos M. Anatomic site of origin of nasal polyps: endoscopic nasal and paranasal sinus surgery as a screening method for nasal polyps in autopsy material. Rhinology. 1994; 33: 1858. [PubMed]

5. Nayak AS, Settipane GA, Pedinoff A, Charous BL, Meltzer EO, Busse WW, Zinreich SJ, Lorber RR, Rikken G, Danzig MR; Nasonex Sinusitis Group. Ann Allergy Asthma Immunol. 2002 Sep; 89(3):271-8.

6. Iinuma T, Hirota Y, Kase Y. Radio-opacity of the paranasal sinuses. Conventional views and CT. Rhinology. 1994; 32: 134-6. [PubMed]

7. Lund V, Mackay IS. Staging in chronic rhinosinusitis. Rhinology. 1993; 31: 183-4. [PubMed]

8. Bernstein JA. Azelastine hydrochloride: a review of pharmacology, pharmacokinetics, clinical efficacy and tolerability. Curr Med Res Opin. 2007 Oct; 23(10): 2441-52.

9. Duraisamy Kempuraj, Manhuang et al; Annals of Allergy, Asthma and Immunology 2002; Volume 88, Issue 5, Pages 501-506, May 2002. 
10. Ratner PH, Van Bavel J, Amar NJ, Daftary P, Wheeler W, Sacks H. Hampel FC1, "Double-blind, placebo- controlled study of azelastine and fluticasone in a single nasal spray delivery device" Ann Allergy Asthma Immunol. 2010 Aug; 105 (2): 168-73. doi: 10.1016/j.anai.2010.06.008.

11. Djupesland PG1, Vlckova I, Hewson G. Impact of baseline nasal polyp size and previous surgery on efficacy of fluticasone delivered with a novel device: a subgroup analysis. American Journal of Rhinology and Allergy; 2010 Jul-Aug; 24 (4): 291-5.

\begin{tabular}{|c|c|c|c|}
\hline SYMPTOMS & GRADE & GROUP I & GROUP II \\
\hline Nasal Obstruction & Mild & 08 & 09 \\
\hline & Moderate & 07 & 08 \\
\hline & Severe & 15 & 13 \\
\hline Nasal Discharge & Mild & 11 & 13 \\
\hline & Moderate & 13 & 09 \\
\hline & Severe & 06 & 08 \\
\hline Excessive Sneezing & Mild & 12 & 08 \\
\hline & Moderate & 09 & 10 \\
\hline & Severe & 09 & 12 \\
\hline Headache & & 16 & 10 \\
\hline Disturbance of Smell & \multicolumn{3}{|c|}{ Table I: Symptoms in Group I and II } \\
\hline \multicolumn{2}{|c|}{} & 12 & 13 \\
\hline
\end{tabular}

\section{ENDOSCOPIC STAGING OF NASAL POLYPS:}

\begin{tabular}{|c|c|c|}
\hline GRADE & GROUP 1 & GROUP 2 \\
\hline Grade 0 & 0 & 0 \\
\hline Grade 1 & 10 & 09 \\
\hline Grade 2 & 09 & 08 \\
\hline Grade 3 & 11 & 13 \\
\hline
\end{tabular}

Table II: Grading of Polypi Group I and Group II

\begin{tabular}{|c|c|c|c|}
\hline GROUP I & NUMBER & GROUP II & NUMBER \\
\hline MALES & 21 & MALES & 24 \\
\hline FEMALES & 09 & FEMALES & 06 \\
\hline \multicolumn{4}{|c|}{ Table III: Sex distribution } \\
\hline
\end{tabular}

\begin{tabular}{|c|c|c|}
\hline Age group & Group I & Group II \\
\hline 20-30 years & 12 & 15 \\
\hline 31-40 years & 11 & 11 \\
\hline 41-50years & 06 & 03 \\
\hline$>$ 50 years & 01 & 01 \\
\hline
\end{tabular}

Table IV: Age distribution 


\section{Group I:}

\begin{tabular}{|c|c|c|c|c|c|c|}
\hline Observation & $n=30$ & $\begin{array}{c}\text { Pt not } \\
\text { responded }\end{array}$ & $\begin{array}{c}\text { Pts } \\
\text { responded }\end{array}$ & $\begin{array}{c}\% \text { of } \\
\text { improved }\end{array}$ & $\begin{array}{c}\text { Pearson } \\
\text { r2 } \\
\end{array}$ & $\begin{array}{c}\mathrm{T} \\
\text { test }\end{array}$ \\
\hline $\begin{array}{c}\text { Nasal } \\
\text { obstruction }\end{array}$ & & & & & 0.75 & 0.06 \\
\hline Mild & 8 & 0 & 8 & 100 & & \\
\hline moderate & 7 & 4 & 3 & 42.9 & & \\
\hline Severe & 15 & 7 & 8 & 53.3 & & \\
\hline Rhinorrhoea & & & & & 0.99 & 0.015 \\
\hline Mild & 11 & 5 & 6 & 54.5 & & \\
\hline Moderate & 13 & 7 & 6 & 46.2 & & \\
\hline Severe & 6 & 2 & 4 & 66.7 & & \\
\hline $\begin{array}{c}\text { Excessive } \\
\text { sneezing }\end{array}$ & & & & & 0.5 & 0.034 \\
\hline Mild & 9 & 1 & 8 & 88.9 & & \\
\hline Moderate & 12 & 5 & 7 & 58.3 & & \\
\hline Severe & 9 & 5 & 4 & 44.4 & & \\
\hline Polypi & & & & & 0.98 & 0.003 \\
\hline Grade I & 10 & 4 & 6 & 60 & & \\
\hline Grade II & 9 & 3 & 6 & 66.7 & & \\
\hline Grade III & 11 & 6 & 5 & 45.5 & & \\
\hline
\end{tabular}

Table V: Group I Analysis of the clinical data before and after medical treatment

\section{Group II:}

\begin{tabular}{|l|c|c|c|c|c|c|}
\hline \multicolumn{1}{|c|}{ Observation } & Before treatment & After treatment & Remaining & \% & R2 & P value \\
\hline Nasal Obstruction & & & & & & \\
\hline Mild & 9 & 5 & 4 & 44.44 & 0.62 & 0.069 \\
\hline Moderate & 8 & 2 & 6 & 75 & & \\
\hline Severe & 13 & 6 & 7 & 53.85 & & \\
\hline \multicolumn{1}{|c|}{ Rhinorrhoea } & & & & & & \\
\hline Mild & 13 & 4 & 9 & 69.23 & 0.98 & 0.035 \\
\hline Moderate & 9 & 3 & 6 & 66.67 & & \\
\hline Severe & 8 & 2 & 6 & 75 & & \\
\hline Excessive Sneezing & & 3 & & & & \\
\hline Mild & 8 & 3 & 7 & 62.5 & 0.87 & 0.031 \\
\hline Moderate & 10 & 5 & 7 & 58.33 & & \\
\hline & 12 & & & & & \\
\hline \multicolumn{1}{|c|}{ Polypi } & & 4 & 5 & 55.56 & 0.98 & 0.039 \\
\hline Grade I & 9 & 3 & 5 & 62.50 & & \\
\hline Grade II & 8 & 6 & 7 & 53.85 & &
\end{tabular}

Table VI: Group II Analysis of the clinical data before and after medical treatment 


\section{REVIEW ARTICLE}

\section{AUTHORS:}

1. M. Mahendra Kumar

2. S. Muneeruddin Ahmed

3. Md. Naveed Ahmed

4. Durga Prasad

\section{PARTICULARS OF CONTRIBUTORS:}

1. Assistant Professor, Department of ENT, Kurnool Medical College, Kurnool, A. P.

2. Professor and HOD, Department of ENT, Viswabharathi Medical College, Kurnool, A. P.

3. Professor, Department of ENT, Gandhi Medical College, Hyderabad, A. P.

4. Senior Resident, Department of ENT, Kurnool Medical College, Kurnool, A. P.

\section{NAME ADDRESS EMAIL ID OF THE} CORRESPONDING AUTHOR:

M. Mahendra Kumar,

Government General Hospital, Attached to Kurnool Medical College, Kurnool, A. P

Email: maimal@rediffmail.com

Date of Submission: 26/06/2014. Date of Peer Review: 27/06/2014. Date of Acceptance: 28/06/2014. Date of Publishing: 07/07/2014. 